\title{
How university students perceive the integration of ICT in their physics courses
}

\author{
Btissam Guennoun ${ }^{1}$, Nadia Benjelloun ${ }^{2}$ \\ ${ }^{1,2}$ Interdisciplinary Laboratory of Research in Didactics of Sciences and Technology (ILRDST), Department of \\ Physics, Faculty of sciences Dhar Mehraz, Sidi Mohammed Ben Abdellah University, PB. 1796 Fez-Atlas, \\ 30003 Morocco \\ btissam.guenoun@usmba.ac.ma \& benjelloun.nadia@yahoo.fr
}

\begin{abstract}
This study attempts to explore the perceptions of engineering science students (3rd and 4th academic year) of the exploitation of Information Technology and Communication (ICT) in physics courses. Emphasis is placed exactly on satisfaction of the students next to the use of PowerPoint presentations (PPT), simulations and filmed experiments.

To achieve these objectives, we conducted a survey in the form of a questionnaire distributed to 151 students in the engineering cycle in the city of Fez (Morocco). The data collected indicate that $93.4 \%$ of students have benefited from the use of Power Point presentations. Among these students only $35.1 \%$ consider that these projected slides are a means of facilitating the course content. In addition, $69.5 \%$ of students surveyed took advantage of simulations and short sequences filmed during these courses, the majority of them (63.6\%) say that these tools help them build their own learning by fostering the intimate link between the course and its application.

These results are particularly interesting in the sense that they are used to assess students' perceptions of the simple Power Point presentations. These presentations alone are not enough to make available the contents of a physics course. They must be integrated into pedagogically appropriate learning situations and accompanied by demonstrations on the board. Finally, to illustrate the physical phenomena and physical laws, it is necessary to enrich these slides by simulations and filmed experiments able to develop the cognitive capacities of the student as regards physics.
\end{abstract}

Indexing terms/Keywords: ICT, Higher Education, Physics, Simulations, Film Clips, Power Point Presentations

\section{Introduction And Problem}

It is certain that the integration of the ICT in the establishments of Moroccan higher education has recently started to gain more and more importance in the environment of scientific disciplines didactics in general and in particular with all its specificities like very concrete disciplines - compared with the other scientific disciplines - and for which teaching requires to be carried out with a particular care based on the observation of facts and phenomena before modeling and mathematizing them.

However, if this integration in itself constitutes a true revival in our university pedagogy, it is strongly necessary to probe the possibility of making this revival more rational and more realistic to study the attitude of the teaching actors more closely, in fact, that of the students themselves towards the use of these techniques knowing that the true obstacles in front of this rationalism and this realism are neither often nor always inherent in the resources but they are also linked and to a large extent to the educational actors; students and teachers.

Previous research has shown that students in general perform formulas and physical laws without getting to master the true concepts and that they find major difficulties to connect the physics courses to experimental practice or to daily life.

Pundak and Rozner (2008) pointed out that the traditional teaching approach of physics fails to help students develop conceptual understanding of the most fundamental concepts.

Posner, Strike, Hewson and Gertzog (1982) raised that learners cannot build a correct representation of a scientific concept only if it is communicated and presented under various modes; experiments, diagrams, symbols, etc....

Richoux, Salvetat and Beaufils (2002) estimated that the teaching of physics is, among other things, to relate reality (phenomena, objects, devices ...) with theories and models designed or imagined by physicist.

Marcel Lebrun (2011) studied the impact of the ICT on the quality of the students learning and the professional development of the teachers of the superior. He raised that technologies are certainly carrying potentials for the teaching development but, in order to withdraw the hoped educational values, they need to be supported by pedagogical devices based on more attractive and interactive methods, supported by new roles of 
actors, teachers and students. And finalized in the development of human, social and professional skills of these actors.

Moroccan previous research has made a first step but a basic one on the long way of the exploration of the problem while trying to study the impact of the use of the ICT on the teaching-learning of the scientific disciplines and in particular physics.

Thus Bouchaïb and Benjelloun (2011) worked out - in a fundamental way- an inventory of the conceptual difficulties observed in the students of the first university cycle in the field of electrostatics. They integrated the resources of the site "University online" (UeL) in a teaching session in présentiel. The results showed that when the resources of UeL are integrated in situation of self-learning accompanied by a tutor teacher, they allow a good appropriation of these concepts and a better interpretation of the situations used like instrument of evaluation. These researchers also reported that a teaching session, enriched by UeL is tiring for a facilitator teacher who must ensure only a technical and conceptual support for the students and follow the progression of the learning of the group. It is beneficial only for restricted groups; the facilitator teacher should give each student a minimum time for an effective learning.

Berrada and Chraïbi (2010) conducted a comparative study between two educational experiments remotely conducted in two Moroccan academics (Engineering School and Faculty of Science). Both devices proposed are based on a social constructivist pedagogy promoting a student-centered learning. These researchers concluded that the progressive and dynamic integration of a learning environment could facilitate the appropriation of courses by students of their institutions and thus contribute to reducing the rate of failure and abandonment. These experiments have identified some difficulties of technical, organizational and pedagogical sides.

Droui and Kaaouachi (2010) noted a problem on the level of the transfer between the theoretical models and physical manifestations of the phenomena studied. They declared that the theoretical exposition does not allow the knowledge sharing and the experiments of learners and it neither leaves a place to the reflection nor it supports the development of experimental know-how

The objective of this work consists on the one hand to determine the most beneficial pedagogical uses of the ICT and to show the least favorable uses for the students as regards the learning of physics. Of another share it is to discover the teaching approach mostly adapted for a better learning of the courses of physics thus announce the objective obstacles relating to the ICT themselves and subjective (in relation to the pedagogical actors) which prevent a reasoned and realistic integration.

\section{Research Questions}

We therefore propose to address two specific issues in this research:

- What perception do students make of the integration of Power Point presentations, simulations and experiments filmed in physics courses?

- Under which conditions, the ICT integrated into the teaching of physics, would be more appropriate for a better teaching-learning of this discipline?

\section{Methodology}

Our study in particular aims at measuring the degree of satisfaction experienced by students of the engineer cycle with regard to the use of the ICT in the courses of physics, knowing their expectations, their needs and the added-value that these tools bring to their learning.

Our research was undertaken before 151 students of the engineer cycle of two establishments of the higher education of the town of Fez in Morocco. This sample is composed of $60.3 \%$ of the students of the national school applied sciences of Fez (ENSAF) and of $39.7 \%$ of the students of the Faculty of Science and Technology of Fez (FSTF) of 3 different specialties: electronic genius, mechatronics genius and genius system embarked / industrial computer.

\section{Results And Discussion}

In this section, the results are presented according to the objective of research which is, let us recall it, determining the perception that the students have towards the integration of the ICT and to determine the most appropriate teaching approach for a better learning of physics courses. The treatment of these results was performed by the Sphinx 4.0 software.

\section{Perception of the use of the ICT in the physics courses by the students of engineering cycle 1.1 Reality of the integration of the TIC in the courses of physics and students attitude}

The cross analysis of the answers given by the students of physics and who had already profited from the use of the ICT, as shown in table I, allows us to note that $72.8 \%$ of them adopt a favorable attitude towards this use. 
Table I. Students Perception of the use of the ICT in the physics courses

\begin{tabular}{|l|c|c|}
\hline Use_ICT_physics_courses & Yes & Total \\
Perception Use_ICT_physics_courses & $72,8 \%(110)$ & $\mathbf{7 2 , 8 \% ( 1 1 0 )}$ \\
\hline For & $27,2 \%(41)$ & $\mathbf{2 7 , 2 \%}(\mathbf{4 1})$ \\
\hline Against & $100 \%(151)$ & \\
\hline TOTAL &
\end{tabular}

The technologies used by these students - except for a minority of $10.6 \%$ - are limited to the software Power Point presentation with a rate of $93.4 \%$, to simulations to explain the abstract notions of the course and the video clips to present the experiments $(69.5 \%)$. (See table II).

Table II. Forms of ICT use in physics courses

\begin{tabular}{|l|c|c|}
\hline \multicolumn{1}{|c|}{ Formes_Use_ICT_Courses } & Nb.cit. & Freq. \\
\hline Course presentation using Power Point software & 141 & $93,4 \%$ \\
\hline Use of simulations and video clips & 105 & $69,5 \%$ \\
\hline Other.... & 16 & $10,6 \%$ \\
\hline TOTAL OBS. & $\mathbf{1 5 1}$ & \\
\hline
\end{tabular}

Note: The number of citations is higher than the number of observations because of multiple answers ( 3 at the most).

Table III presents the materials of the physics whose courses were exempted using these tools.

It can be noted that the frequency of this use is not the same in all the materials addressed by the students of physics at the university in Morocco. Thus we can notice clearly that the material where the ICT has been more integrated is the electronics with a usage rate of $41.1 \%$ whereas the material which profits the less from these technologies is electricity with a usage rate of $7.3 \%$. (See table III)

Table III. Physics materials whose courses were exempted using the ICT

\begin{tabular}{|l|l|l|}
\hline Materials & Nb. Cit & Freq. \\
\hline No answer & 39 & $25.8 \%$ \\
\hline Thermodynamic & 17 & $11.3 \%$ \\
\hline Mechanical & 59 & $39.1 \%$ \\
\hline Electricity & 11 & $7.3 \%$ \\
\hline Electronics & 62 & $41.1 \%$ \\
\hline Optical & 12 & $7.9 \%$ \\
\hline Electromagnetism & 15 & $9.9 \%$ \\
\hline Electro technical & 14 & $9.3 \%$ \\
\hline Automatic & 35 & $23.2 \%$ \\
\hline Hydraulic & 24 & $15.9 \%$ \\
\hline Industrial Computing & 17 & $11.3 \%$ \\
\hline Signal Processing & 19 & $12.6 \%$ \\
\hline Materials Science & 38 & $25.2 \%$ \\
\hline Other & 16 & $10.6 \%$ \\
\hline TOTAL OBS. & $\mathbf{1 5 1}$ & \\
\hline
\end{tabular}

Note: The number of citations is higher than the number of observations because of multiple answers (13 at the most).

For determining a better perception that the students make of physics in Morocco of the use of the ICT in their varied courses, it is important to throw a glance on the arguments they advance to justify their attitude towards this use.

Our investigation has shown us that $72.8 \%$ of students who affirm to be led during their training to better learning with ICT, only $49 \%$ were able to justify their views. The analysis of their justifications also shows that $33.1 \%$ of them consider that the ICT enrich, and instigate, the contents of physics courses and promote a better learning of the material; $5.3 \%$ declare that the ICT improve their motivation to understand physics and help them to progress; $10.6 \%$ consider that the ICT accelerate their learning and offer to the teachers the opportunity to give deepened examples and explanations on the concepts approached in progress.

According to these justifications one could say well that the integration of the ICT brings easy and affluent access to learning physics courses insofar as it allows a thorough learning at $72.8 \%$ of the students of the engineer cycle.

In contrast, $27.2 \%$ (table I) of the students having answered our questionnaire consider that the use of the ICT is not always adequate nor always relevant. $11.3 \%$ among them are unable to be justified while $2 \%$ declare that the utility of the ICT lies only in the fact that they help to accelerate the presentation of the courses; $6 \%$ estimate that the ICT do not allow an integral assimilation of all the notions of the course and insist on the 
need to use the demonstrations in the table; $4.6 \%$ consider that the regular and frequent use of ICT often causes the trouble ; $3.3 \%$ affirm that the inappropriate use of the ICT slows down their process of learning.

One can deduce from the results of our investigation that the integration of the ICT in the teaching of physics is certainly advantageous for the university students and that it improves, certainly, the quality of their learning; however these tools should be used in didactic situations based on techno-pedagogic approaches where other supports of teaching are also exploited.

By basing us on these data, we can estimate well with Laure Endrizzi (2012) that it does not mean to know if it is relevant to use the ICT in a formal context of education or training but to reflect on the optimum conditions for a successful integration. Because they should always be integrated, and this integration requires approaches which exceed the pioneer practices of some auto--convinced teachers.

\subsection{Student's perception of the use of the power point presentations in the physics courses}

The answers collected from the students in table IV that introduce a cross analysis show us that among the $93.4 \%$ of the students having profited from the Power Point presentations in courses of physics, $35.1 \%$ estimate that these presentations make the courses more accessible and easier to assimilate whereas $58.3 \%$ do not approve their use at all.

Table IV. Student's perception of the added-value of PPT in the physics courses

\begin{tabular}{|l|c|c|c|}
\hline \multicolumn{1}{|c|}{ Use_PPT } & Yes & No & TOTAL \\
\hline Perception_PPT Use & $0,0 \%(0)$ & $6,6 \%(10)$ & $\mathbf{6 , 6 \%}(\mathbf{1 0})$ \\
\hline Fo answer & $35,1 \%(53)$ & $0,0 \%(0)$ & $\mathbf{3 5 , 1 \%}(\mathbf{5 3})$ \\
\hline Against & $58,3 \%(88)$ & $0,0 \%(0)$ & $\mathbf{5 8 , 3 \%}(\mathbf{8 8})$ \\
\hline TOTAL & $\mathbf{9 3 , 4 \% ( 1 4 1 )}$ & $\mathbf{6 , 6 \% ( 1 0 )}$ & \\
\hline
\end{tabular}

A preliminary analysis of the justifications provided by the students having a positive perception of the use of PPT presentations in the course of physics (35.1\%) revealed us the following data: $2 \%$ among them see that these presentations help to synthesize and to structure the notes of the course; 5.3\% estimate that PPT render the course clearer and better structured; 7.9\% find that PPT enriched by simulations and experiments in videos make the course more comprehensible and that finally $9.9 \%$ determine that PPT help them follow better and advance more quickly in the course. The rest, a rate of $9.9 \%$ keeps a good attitude towards the use of these presentations without justifying their point of view.

As for the students who adopt a completely unfavorable attitude to the use of PPT presentations (a rate of 58.3\%) our investigation on ground led us note the following results: $4.6 \%$ of them find that PPT only summarize the course content; $14.6 \%$ estimate that these presentations make the course rather boring and only help to accelerate its presentation; $22.5 \%$ see that it is necessary that the teachers add detailed explanations on the board; $1.3 \%$ prefer that PPT are accompanied by a handout reiterating the essence of the course of physics whereas $15.2 \%$ were simply satisfied to express their unfavorable attitude without any explanation.

All in all, one could say that for $35.1 \%$ of the students, the use of the power point presentations in a course of physics brings an easy and affluent access to its scientific contents and improves the learning of this discipline, however $58.3 \%$ advance that if these presentations are badly exploited, their use will rather disadvantage the access to the contents of the courses of physics, since the abstract parts of these courses require detailed explanations on behalf of the teacher and demonstrations on the board enriched by simulations, animations, short filmed sequences ... and accompanied by a handout reiterating the essence of the course of physics. That brings us clearly closer theoretical level, to the work of Raby, Karsenti, Miller and Villeneuve (2011) which showed that the possible integration of graphs, images, animations and short video sequences in the power point presentations enriches and instigates the contents of the course, while supporting a better comprehension of the material. Laure Endrizzi (2012) also declared that these technologies encouraging the cognitive activity have a better influence than those being used to present or to make available from the contents and that if the interactions with the teacher and between the students can influence the learning positively, these however are the modalities relating to the mediation of the content itself that have the utmost effect.

It clearly appears from our results that a simple presentation of the course using power point is not sufficient to make the contents of the course of physics easy to assimilate. In order to understand, model or explain the physical phenomena and laws, these presentations must be integrated in situations of learning, pedagogically adequate and enriched by the TIC tools (explanatory Diagrams, filmed simulations, experiments.) developing the innovating capacities of the student in physics. The didactic and pedagogic competences of the professor related to technologies still remain the crucial factors of a successful use of the slides projected in a session of the course of physics. 


\subsection{Student's perception of the use of simulations and video clips in the courses of physics}

Table $\mathrm{V}$ shows the cross analysis of the answers of the students concerning their perception of the courses of physique integrating the simulations and video clips.

Table V. Students' perception of the added value of simulations and video clips in physics courses

\begin{tabular}{l} 
Perception_Use simulations+ video clips \\
\hline No answer
\end{tabular}

Use_simulations + video clips

For

Against

TOTAL

\begin{tabular}{|l|l|l|}
\hline \multicolumn{1}{|c|}{ Yes } & \multicolumn{1}{|c|}{ No } & \multicolumn{1}{c|}{ TOTAL } \\
\hline $0,0 \%(0)$ & $30,5 \%(46)$ & $\mathbf{3 0 , 5 \% ( 4 6 )}$ \\
\hline $63,6 \%(96)$ & $0,0 \%(0)$ & $\mathbf{6 3 , 6 \%}(\mathbf{9 6})$ \\
\hline $6,0 \%(9)$ & $0,0 \%(0)$ & $\mathbf{6 , 0} \%(\mathbf{9})$ \\
\hline $\mathbf{6 9 , 5 \% ( 1 0 5 )}$ & $\mathbf{3 0 , 5 \% ( 4 6 )}$ & \\
\hline
\end{tabular}

The results of our study as presented in table $\mathrm{V}$ show that $69.5 \%$ of the students have benefited from simulations and the short sequences filmed in the courses of physics.

Among the $63.6 \%$ of the students having appreciated this use : $16.6 \%$ judge that these tools make it possible to facilitate the acquisition of the difficult scientific concepts and help according to $20.5 \%$, to develop the comprehension about the phenomena and physical laws. A good part of students, a rate of $26.5 \%$ were not justified on this subject.

According to these results, the integration of the interactive digital resources has a positive impact on the learning of the physical phenomena.

In this sense, Ahaji, El Hajjami, Ajana, El Mokri and Chikhaoui (2008) showed that the integration of optical simulation sequences can promote specific learning processes to scientific students, as well as the establishment of a learning environment directed towards the construction of knowledge. These results also make us think of the work of Bouchaïb and Benjelloun (2011) which showed that simulations and animations make it possible for $85 \%$ of the students to have a better representation of the concepts of electrostatics. That is what makes the learning of this discipline more attractive and motivating than a classical session.

$6 \%$ of the students having answered the questionnaire of our investigation do not see the utility of simulations and short film clips which are, according to them, often badly exploited in a course of physics. They declare that these tools cannot be interesting only if they are combined with suitable learning methods. These attitudes also make us think of the work of Droui, El hajjami, Bouklah and Zouirech (2013) that estimate on their part that in a constructivist learning environment supported by a simulation, dissatisfaction emerges when the student is confronted with results in conflict with his own predictions.

According to our investigation, one could note a strong appreciation - in students of the engineer cycle - about the use of the simulations and short sequences filmed in the physics courses.

One can also affirm, with the researchers cited in this study that the simulations and the experiments filmed that are effectively exploited and regularly combined with decorous learning methods are very positive effects on the assimilation of a physics course at the university.

\subsection{Student's perception of the use of the internet sites in relation to the content of the physics courses}

According to our questionnaire/investigation, $92.1 \%$ of the students have already accessed, apart from the education meeting at websites in link with the contents of the of physics courses. Table VI summarizes a cross analysis of our results.

Table VI. Student's perception of the use of the websites

\begin{tabular}{|l|l|l|l|}
\hline Perception_use_websites & \multicolumn{1}{|c|}{ Yes } & \multicolumn{1}{|c|}{ No Websites } & \multicolumn{1}{c|}{ TOTAL } \\
\hline No answer & $0,0 \%(0)$ & $7,9 \%(12)$ & $\mathbf{7 , 9 \%}(\mathbf{1 2})$ \\
\hline For & $86,8 \%(131)$ & $0,0 \%(0)$ & $\mathbf{8 6 , 8 \%}(\mathbf{1 3 1})$ \\
\hline Against & $5,3 \%(8)$ & $0,0 \%(0)$ & $\mathbf{5 , 3 \%}(\mathbf{8})$ \\
\hline TOTAL & $\mathbf{9 2 , 1 \% ( 1 3 9 )}$ & $\mathbf{7 , 9 \% ( 1 2 )}$ & \\
\hline
\end{tabular}

This cross analysis teaches us on the one hand that $86.8 \%$ of the students find that the access to websites in relation to the contents of their physics course makes it possible to better understanding of the lectures and deepening even into further knowledge relative to the course. Of another share one notes according to the same analysis that $28.5 \%$ among these students find that there are complementary contents related to the courses learned at the university. In addition, $17.2 \%$ see that these sites present the courses of physics in a structured way and support the comprehension of certain problems approached in progress and $11.3 \%$ find that the diagrams, the images, simulations and the experiments filmed and being reproduced on the websites, make the courses of physics more accessible. Besides these rates of students are clearly favorable to the use of the websites within the framework of their discipline $5.3 \%$ note that the courses, the exercises, the problems and the examinations corrected available on websites help well to perfection of knowledge in physics. However, 24.5\% haven't given any judgment on this use. In contrast, $5.3 \%$ of the students are not favorable to 
the use of the Internet in the learning of physics. Except the $2.6 \%$ of the future engineers who did not justify their unfavorable opinion with regard to this use, $2 \%$ see that the exploitation of these sites requires efforts and time to draw the best; $0.7 \%$ go until saying that these sites can sometimes contain false information and others thwarting even to what they have seen in progress with their professors.

These results reflect in our opinion a lack of skill in these future engineers to use Internet in their learning of physics and a lack of confidence towards the use of the digital resources available on the Web from where comes the need for a formation in this field for a better investment of these resources in the learning of physics.

Indeed, these various views of the students in Morocco go in the same direction or almost with a study made by Menvielle (2011) according to which a course in présentiel constitutes a weekly appointment, very often impossible to circumvent for a student whose obligation to meet the professor avoids the scattering of the activities at the time of the follow-up of a course and supports the success of the previous one.

Other studies like those of Raby, Karsenti, Meunier and Villeneuve (2011) add, moreover, that the access to websites suggested by the trainer and in link with the contents of the course constitutes an advantageous element of the ICT since the students can thus refer to it to reach complementary contents related to the course, to become acquainted with a concrete illustration of certain problems approached in progress, to explore a subject of interest more, to profit in a different way to explain the concepts seen during the course, etc. This access in particular enables them to better exploit the lectures, to improve their comprehension, to look further into their knowledge and to push their reflection further, as these researches let us understand.

All in all, to motivate the students to more use of the digital resources available on the Web, the teachers are brought to subject devices of teaching online illustrating the contents of the course of physics with a framing of quality.

\section{Point of view of the students of the engineer cycle of the approach of teaching the most adapted for a better learning of the courses of physics.}

The objective of this study is to explore the impact of the ICT on the learning of the physics courses by the university students, to evaluate the most adapted teaching approach for a better learning of physics through the forms of the courses to which the students have usually access.

Table VII. Views of the scientific students of the most adapted teaching approach for a better learning of physics courses.

\begin{tabular}{|l|c|c|}
\hline \multicolumn{1}{|c|}{ Pedagogical approach_physics_courses } & Nb.cit. & Freq. \\
\hline Teaching of physics courses given on the board with handout & 21 & $13,9 \%$ \\
\hline Teaching of physics courses integrating ICT + handout & 76 & $50,3 \%$ \\
\hline Hybrid teaching (ICT + demonstrations on the board + handout) & 54 & $35,8 \%$ \\
\hline TOTAL OBS. & $\mathbf{1 5 1}$ & $\mathbf{1 0 0 \%}$ \\
\hline
\end{tabular}

As table VII shows it clearly, $13.9 \%$ of the respondents prefer a traditional teaching on the board accompanied by a written support incorporating the essential of the physics course. These students choose a traditional teaching on the board for all the courses of physique requiring demonstrations. One could easily see that the main obstacle here in front of the investment of the digital resources is rather due to a lack of skill and motivation towards their handling during the sessions of the course.

What appears to us of great importance in the results indicated by table VII is that $50.3 \%$ of the students having answered our investigation are for a teaching integrating information technology and communication of ICT accompanied by a handout listing the essence of the course. These students affirm that the use of ICT during the sessions of the physics course help them to better understand and advance more quickly in the course and the presence of a handout encourage them to better follow and keep a hard copy of the course. These results remind us of many works like those of Berrada and Chraïbi (2010) which supported that the various tools of communication and interaction facilitate the shoring between the students and their appropriation of the course.

Another view of the approach of physics is the one which represents a rate of $35.8 \%$ of the respondents who have chosen a hybrid teaching where the course of physics is given on the board and enriched by the simulations, the filmed experiments and a handout listing the essence of the course. These students confirm that hybrid teaching is the most appropriate medium for a full and thorough assimilation of different concepts in physics.

To conclude, one could say that the use of ICT in a physics course constituted for $50.3 \%$ of the students a very strong added value. Moreover, the presence of a handout help them to focus, to better follow the explanations and to retain the essence of the course without wasting time in taking notes. These students benefit initially from the explanations of the teacher, simulations which clear up the abstract notions of the course and the video clips presenting the experiments relating to the course while keeping a detailed hard copy of the taught 
contents. Regular and effective use of ICT in this way in a teaching session remains the most appropriate method for a full and deep assimilation of difficult concepts in physics. However, it remains always dependent on the nature of the material taught requiring the demonstrations detailed on the board, on the skill and the motivation of the students to learn this kind of course and pedagogy adopted to teach it.

\section{Statistical study}

3.1 Test of independence of chi2 between the Pedagogical approach opted by the students of the engineer cycle and their perception to the use of ICT in physics courses

We studied using the test of independence of Chi2, the relation between the teaching approach favored by the students of the engineer cycle and the perception they made of the use of the ICT in their physics courses (table VIII). It is then a question of studying the dependence between the two following variables:

- Perception Use_ICT_physics_courses : Students' perception of the use of ICT in physics courses

- Pedagogical approach_physics_courses : Pedagogical approach favored by the students for a better learning of the physics courses

We drew the following working hypotheses:

Null hypothesis H0: The pedagogical approach adopted by the students of the engineer cycle does not depend on their perception of the use of ICT in physics courses.

Alternative hypothesis H1: The pedagogical approach adopted by the students of the engineer cycle depends on their perception of the use of ICT in physics courses.

Table VIII recapitulates the got results:

Table VIII. Dependence between the pedagogical approach adopted by the students of engineer cycle and their perception of the use of ICT in physics courses

\begin{tabular}{|l|l|l|l|}
\hline $\begin{array}{c}\text { Perception Use_ICT_physics_courses } \\
\text { Pedagogical approach_physics_courses }\end{array}$ & \multicolumn{1}{|c|}{ For } & \multicolumn{1}{|c|}{ Against } & \multicolumn{1}{|c|}{ TOTAL } \\
\hline Teaching of physics courses given on the board with handout & $2,0 \%(3)$ & $11,9 \%(18)$ & $\mathbf{1 3 , 9 \% ( 2 1 )}$ \\
\hline Teaching of physics courses integrating ICT + handout & $50,3 \%(76)$ & $0,0 \%(0)$ & $\mathbf{5 0 , 3 \% ( 7 6 )}$ \\
\hline Hybrid teaching (ICT + demonstrations on the board + handout) & $20,5 \%(31)$ & $15,2 \%(23)$ & $\mathbf{3 5 , 8 \% ( 5 4 )}$ \\
\hline TOTAL & $\mathbf{7 2 , 8 \% ( 1 1 0 )}$ & $\mathbf{2 7 , 2 \% ( 4 1 )}$ & \\
\hline
\end{tabular}

Note: The boxes framed in blue (pink) are those for which the actual number is much higher (lower) than the theoretical number. The values of the table are the percentages to the total established on 151 observations The results of Chi-square Statistical Test are presented in table IX below:

Table IX: The results of Chi-square Statistical Test

\begin{tabular}{|c|c|c|c|}
\hline Chi- square Value & The degree of freedom $:$ ddl & $\begin{array}{c}\text { Interval of critical probability } \\
: \mathbf{P}\end{array}$ & The accepted hypothesis \\
\hline 71.25 & 2 & $\mathrm{P}<=0.01$ & $\mathrm{H} 1$ \\
\hline
\end{tabular}

In this case the Chi2 test showed a very significant dependence between the pedagogical approach opted by the students of the engineer cycle and their perception of the use of ICT in the physics courses. These results confirm the rejection of the $\mathrm{H} 0$ hypothesis and the maintenance of the $\mathrm{H} 1$ hypothesis.

It appears clearly (Table VIII) that $72.8 \%$ of students who have a positive perception of the use of ICT in physics courses $70.8 \%$ among them turn towards an approach of teaching not purely traditional: $50.3 \%$ are for a teaching of physics courses integrating the ICT accompanied by a handout, whereas $20.5 \%$ are for a hybrid teaching (ICT + demonstration on the board + handout)

One can deduce from our results that taking into account the nature of the material taught, a development of the demonstrations in a more detailed way on the board accompanied by a handout, will make a judicious use of the ICT in the physics courses more appreciable and will constitute a help for the success of the students in physics.

\section{Conclusion}

According to the results of our study, the appropriate use of simulations and short sequences filmed in physique courses integrating the ICT appears as being the pedagogical practice most favorable to the learning of the students whereas the teaching practices least favorable to their learning are in particular the bad exploitations of the Power Point presentations which make the physics courses difficult to assimilate. The results show us that the university students are mainly against a simple presentation of the physics course using power point software whereas an appropriate integration of simulations and experiments filmed in the projected slides, based on adequate techno-pedagogic methods supplemented by explanations and demonstrations detailed on the board 
and accompanied by a handout reiterating the essence of the course, constitute a major help for the success of the students in the material of physics.

This work enabled us to understand that the success of the learning of the physics courses using the ICT requires first of all, a strong motivation of the university students to learn, observe and simulate at the same time a physics course by the means of the ICT. It requires, then, that the university students have one (self-) training allowing them to acquire the necessary skills to learn with new technologies and it requires, still, a relevant integration of the ICT in adequate situations of learning, centered on the needs of the students, and asks, finally, for a development of the more detailed demonstrations on the board during the sessions of the course according to the complexity of the taught material without neglecting the publication of the devices of teaching online adapted to suitable teaching methods that are more active, recommended and suggested by the tutorteacher outside of the teaching sessions and in link with the contents of the courses of physics.

All in all, a good exploitation will be able to contribute to the development of the physics teaching within the university and will open up the way for a generalized use of the ICT in higher educations of the physics in a more rational and more realistic way.

\section{References}

[1] Pundak, D., \& Rozner, S. (2008). Empowering engineering college staff to adopt active learning methods. Journal of Science Education and Technology, 17(2), p. 152-163.

[2] Posner, G.J, Strike, K.A, Hewson, P.W. \& Gertzog, W.A. (1982). Accomodation of a scientific conception: Toward a theory of conceptual change. Science Education. 66(2), p. 211-227.

[3] Richoux, B., Salvetat, C., \& Beaufils, D. (2002). Simulation numérique dans l'enseignement de la physique: enjeux, conditions. Bulletin de l'Union des Physiciens, 842, p. 497-522.

[4] Lebrun, M. (2011). Impacts des TIC sur la qualité des apprentissages des étudiants et le développement professionnel des enseignants: vers une approche systémique. Revue des Sciences et Technologies de l'Information et de la Communication pour l'Education et la Formation (STICEF), 18. Available on the site of the review : http://sticef.univ-lemans.fr

[5] Bouchaïb, A. \& Benjelloun, N. (2011). Impacts des TIC sur l'enseignement et l'apprentissage des conceptions relatives au champ électrostatique en classes préparatoires aux grandes écoles d'ingénieurs (CPGE). Revue internationale des technologies en pédagogie universitaire, 8 (3), p. 66-80. Available on the site of the review : http://www.ritpu.org

[6] Berrada, W. \& Chraïbi, S. (2010, Mai). Comparaison d'expériences d'insertion de dispositifs technopédagogiques dans le milieu universitaire marocain. Communication présentée au 26ème congrès international de l'Association internationale de pédagogie universitaire (AIPU): réformes et changements pédagogiques dans l'enseignement supérieur à la faculté des sciences de l'éducation, Rabat, Maroc.

[7] Droui, M. \& Kaaouachi, A. (2010, mai). L'intégration et l'usage des TIC dans l'enseignement des sciences à l'université : cas de l'Université Mohammed Premier. Communication présentée au $26^{\text {ème }}$ congrès international de l'Association internationale de pédagogie universitaire (AIPU): réformes et changements pédagogiques dans l'enseignement supérieur à la faculté des sciences de l'éducation. Rabat, Maroc.

[8] Endrizzi, L. (2012). Les technologies numériques dans l'enseignement supérieur, entre défis et opportunités. Dossier d'actualité Veille et Analyses, (78). Recovered of the site of the French Institute of education : http://ife.ens-lyon.fr

[9] Raby, C., Karsenti, T., Meunier, H. \& Villeneuve, S. (2011). Usage des TIC en pédagogie universitaire : Point de vue des étudiants. Revue internationale des technologies en pédagogie universitaire (RITPU), 8(3),6-19. Available on the site of the review: http://www.ritpu.org.

[10] Ahaji, K., El Hajjami, A., Ajana, L., El Mokri, A., \& Chikhaoui, A. (2008). Analyse de l'effet d'intégration d'un logiciel d'optique géométrique sur l'apprentissage d'élèves de niveau baccalauréat sciences expérimentales. EpiNet: revue électronique de l'EPI, 101. Recovered of the site of association Public education and Data processing : http://www.epi.asso.fr

[11] Droui, M., El Hajjami, A., Bouklah, M., \& Zouirech, S. (2013). Impact de l'apprentissage par problème sur la compréhension conceptuelle de la mécanique newtonienne. EpiNet : Revue électronique de l'EPI, 157. Recovered of the site of association Public education and Data processing: http://www.epi.asso.fr

[12] Menvielle, W. (2011). Une analyse longitudinale de la réussite des étudiants « en ligne» ou « en classe »: le cas d'un cours de marketing suivi au sein d'une université québécoise. Revue internationale des technologies en pédagogie universitaire (RITPU), 8(3), 20-35. Available on the site of the review : http://www.ritpu.org 